Business and Economics Research Journal

Volume 7 Number 32016

pp. $39-52$

ISSN: $1309-2448$

DOI Number: 10.20409/berj.2016321807

\title{
Finansal Gelişme ve Ekonomik Büyüme ilişkisi: 1990-2014 Yılları Zordaki Onlu Ülkeler Uygulaması
}

\author{
Sümeyra Gazel ${ }^{\mathrm{a}}$
}

\begin{abstract}
Öz: Bu çalışma finansal gelişme ve ekonomik büyüme arasındaki ilişkinin zordaki onlu ülkeler (Brezilya, Kolombiya, Şili, Güney Afrika, Güney Kore, Peru, Rusya, Tayland, Singapur ve Tayvan) için araştırılmasını amaçlamaktadır. Bu kapsamda zordaki onlu ülkeler 1990-2014 yılları için Dinamik Sabit Etkiler ve Ortak ilişsili Etkiler Ortalama Grup tahmincisi ile incelenmiştir. Çalış̧mada Kişi Başına Gayri Safi Yurtiçi Hasıla ekonomik büyümeyi temsil etmek üzere kullanılmıştır. Diğer yandan finansal geliş̧meyi temsilen Geniş Para Arzının (M2), Gayri Safi Sermaye Oluşumunun (GCF) ve Özel Sektöre Sağlanan Yurtiçi Kredilerin (DCP) Gayri Safi Yurtiçi Hasılaya (GSYH) olan yüzdeleri kullanıılmıştır. Araştırma sonuçları uzun ve kısa dönem için farklı sonuçlara işaret etmektedir. Sonuçlar incelenen veriler kapsamında uzun dönemde finansal gelişme ve ekonomik büyüme arasında bir ilişkinin olmadığını ancak kısa dönemde zayıf bir pozitif ilişkinin varlığını göstermektedir.
\end{abstract}

Anahtar Sözcükler: Finansal Gelişme, Ekonomik Büyüme, Zordaki Onlu Ülkeler, Panel Veri Analizi

JEL Sınıflandırması: C33, E44, O11

\section{The Relationship Between Financial Development and Economic Growth: An Analysis on Troubled Ten Countries 1990 -2014}

\begin{abstract}
This study aims to investigate relationship between financial developments and economic growth for troubled ten countries (Brazil, Colombia, Chile, South Africa, South Korea, Peru, Russia, Thailand, Singapore and Taiwan). In this context, troubled ten countries have been examined with dynamic fixed effects estimator and Common Correlated Effects Mean Group for the years 1990-2014. Gross Domestic Product per Capita was used as a proxy for economic growth in the study. On the other hand, Broad Money, Gross Capital Formation and Domestic Credit to Private Sector (\% of GDP) are used as proxies for financial development. The results point to different for the long and short term. The results demonstrate that there isn't a relationship between financial development and economic growth in the context of analyzed long-term. However, it is possible to say that there is a weak positive relationship between financial development and economic growth in short term.
\end{abstract}

Keywords: Financial Development, Economic Growth, Troubled Ten Countries, Panel Data Analysis

JEL Classification: C33, E44, O11

\footnotetext{
a Assist. Prof. Dr., Bozok University, Faculty of Economics and Administrative Sciences, Department of Business Administration, Yozgat, Turkiye, sumeyra.gazel@bozok.edu.tr
} 


\section{Giriş}

Ekonomik büyüme kavramı hem gelişmiş hem gelişmekte olan ülkeler için önemli bir konu olup en genel tanımı ile bir ülkede üretilen mal ve hizmetlerde meydana gelen artışı ifade etmektedir (Gül ve Ergün, 2012, 127). Ekonomik büyüme, bir ülkede üretilen tüm mal ve hizmetlerdeki (çıktı) artış oranının o ülkenin nüfus artış hızından daha fazla olmasıyla Kişi Başına Gelirin artış oranında sürekliliğin sağlanmasıdır (Todaro ve Smith, 2012, 14). Başka bir ifade ile ekonominin büyüme oranı reel GSYiH'nın artış oranını ifade etmektedir (Dornbusch ve Fischer, 1998, 11).

Finansal gelişme ve ekonomik büyüme arasındaki ilişki literatürde sıklıkla karşılaşılan konular arasında yer almakta ve aralarındaki nedenselliğin yönüne ilişkin farklı bulgulara rastlanmaktadır. Finansal gelişme ve ekonomik büyüme arasındaki nedensellik ilişkisini açıklamaya ilişkin çalışmaların güncelliğini günümüze kadar koruduğunu söylemek mümkündür. Özellikle gelişmekte olan ülkelerin kalkınma çabaları ve bu çabalar içerisinde tasarrufların ve yatırımların rolü tartışmalara dahil edilen konular arasında yer almaktadır. Tasarrufların ekonomiye yönlendirilmesinde gelişmiş bir finansal sisteme ihtiyaç duyulduğu ve kaynak yetersizliğinin gelişmekte olan ülkeler için önemli bir problem olduğu dikkate alınırsa, özellikle gelişmekte olan ülkeler için finansal gelişme-ekonomik büyüme konusu daha da fazla önem kazanmaktadır.

Finansal krizlerden kolay etkilenebilen gelişen ekonomiye sahip ülkelerde finansal gelişimin desteklenmesi birçok kişi ve kurum için önemli ve pozitif sonuçların oluşmasına yardımcı olmaktadır. Bu konular özellikle 2007 yılında ABD'de yaşanan Mortgage krizi gibi dönemlerde dikkat çekmektedir (Anwar ve Nguyen, 2009). Levine'e (1997) göre finansal gelişme ve ekonomik büyüme arasındaki nedenselliği ortaya koyan ampirik çalışmalar hükümetlere finansal sektör reformlarına öncelik verilip verilmemesi konusunda yardımcı olabilmektedir. Ang (2008) ise büyümeyi teşvik etmek amacıyla finansal sistemin genişletilmesini amaçlayan politikaların oluşturulmasının önemine işaret etmektedir. Finansal sistemin genişletilmesi tasarruf-yatırım süreci ve dolayısıyla ekonomik büyüme üzerine pozitif bir etki oluşturabilmek için daha fazla finansal kurumun ve daha geniş bir finansal ürün ve hizmetin varlığını gerektirmektedir.

Literatürde sıklıkla tartışılan konular arasında yer alması, hükümetlerin finansal sektöre ilişkin politikalarını sorgulatması ve gelişmekte olan ülkeler için özellikli bir öneme sahip olması nedeniyle finansal gelişme ve ekonomik büyüme arasındaki ilişki bu çalışma kapsamında "zordaki onlu" (troubled ten) ülkeler için araştırılmıştır.

Amerika Merkez Bankası (FED), Mayıs 2013'te tahvil alım politikasında bir değişliğe gideceğini açıklamış ve açıklama ile birlikte bu politika değişliğinden en fazla etkilenecek ülkeleri Morgan Stanley "kırılgan beşli" (Hindistan, Endonezya, Brezilya, Türkiye ve Güney Afrika) olarak adlandırmıştır (Akel, 2015, 75). Bu açıklama ile birlikte kırılgan beşli olarak adlandırılan ülkelerden önemli derecede sermaye çıkışı gerçekleşmiş ve ülkelerin para birimleri oldukça değer kaybetmiştir. Morgan Stanley'in Kırılgan Beşli'sinin artık konuşulmamaya başlandığı bir dönemde, analistler Ağustos 2015'te Çin'in Yuanı devalüe etmesiyle birlikte bu durumdan olumsuz etkilenmesi beklenen ülkeler hakkında endişelerini dile getirmeye başlamışlardır.

Dünyanın en büyük ikinci ekonomisi olan Çin Halk Cumhuriyetinin büyüme rakamlarının özellikle en büyük ticari ortaklarına olan ihracat talebinin azalmasıyla beraber düştüğü görülmektedir. Çin'in büyüme rakamlarındaki gerilemenin devam etmesi Çin Merkez Bankası'nı (PBOC) para birimi Yuan'ı devalüe etmeye yönlendirmiştir. Çin Merkez Bankası Yuan'ın günlük referans kurunu Ağustos 2015'te yüzde 1.9 düşürmüş ve bunun sonucu Yuan, resmi ve piyasa kurlarının birleştirildiği Ocak 1994'ten bu yana en hızlı bir günlük düşüşünü gerçekleştirmiştir. Çin'in Yuan'ı üst üste devalüe etmesi küresel piyasalarda sarsıntı yaratmış ve Asya hisse senetlerinde dört yılın en büyük iki günlük düşüşü gerçekleşmiştir. Düşüşün daha da büyüyebileceği endişesi ihracat ve emtia fiyatlarının da düşmesine neden olmuş ve küresel bir deflasyon tehdidi konuşulmaya başlanmıştır. Böylece Çin'in Yuan'ı devalüe etmesinden en fazla etkilenecek olan ekonomiler dikkat çekmeye başlamıştır. Çin ile ticari ilişkileri yüksek olan ve Yuan'ın değer kaybetmesinden olumsuz etkilenebilecek ülkeler "zordaki onlu" ülkeler olarak tanımlanmışır. Bu ülkeler, Brezilya, Kolombiya, Şili, Güney Afrika, Güney Kore, Peru, Rusya, Tayland, Singapur ve Tayvan'dır (Worrachate ve Xie, 2015). 
Zordaki onlu ülkelerin Çin ile olan ihracatları incelendiğinde en büyük pay \%37'lik oran ile Güney Afrika'ya aittir. Avusturya \%35'in üzerindeki payı ile ikinci sırada yer almaktadır. İhracatının \%30'unundan fazlasını Çin'e gerçekleştiren Güney Kore ise üçüncü sıradadır. Tayvan için bu oran \%25'i geçerken Tayland için \%15, Singapur için \%12' den daha fazla bir oranı göstermektedir.

Zordaki onlu ülkelerin para birimlerinin sene başından bu zamana dolar karşısındaki değerini incelemekte ülkelerin genel durumu hakkında bilgi verebilir. Bu süreçte para birimlerinin tamamı dolar karşısında değer kaybına uğramıştır. Brezilya Real'i \%23.7, Kolombiya Pezo'su \%20.6, Şili Pezo'su \%11.4, Güney Afrika Randı \%10.1, Peru Yeni Sol'u \%8.1, Güney Kore Won'u \%7.8, Rus Rublesi \%7.5, Tayland Baht'ı \%7, Singapur Dolar'ı\%5.9 ve Tayvan Doları \%2.4 dolar karşısında değer kaybetmiştir. Özetle dünyanın en büyük ekonomilerinden olan Çin ekonomisindeki olumsuzlukların başta zordaki onlu ülkeler olmak üzere birçok ülkeyi sıkıntıya düşüreceği beklenmektedir.

Çalışmanın birinci bölümünde finansal gelişme ve ekonomik büyümeye ilişkin genel kavramlara değinilerek zordaki onlu ülkelere ilişkin bilgilere yer verilmiştir. İkinci bölümde finansal gelişme ve ekonomik büyüme ilişkisinin ele alındığı temel araştırmalara değinilmiştir. Üçüncü bölümde zordaki onlu ülkeler için finansal gelişme ve ekonomik büyüme arasındaki kısa ve uzun dönemli ilişkiyi tespit edebilmek için dinamik sabit etkiler tahmincisine yer verilmiştir. Son bölümde ise sonuçlar özetlenmiş ve kısa bir değerlendirmede bulunulmuştur.

\section{Literatür}

Finansal gelişmeden temel olarak anlaşılan, tasarrufların arttırılması ve bu tasarrufların yatırım birimlerine ulaşmasının kolaylaşmasıdır. Finansal liberalleşme politikalarının başarısı, ülkedeki tasarrufları arttırabilme kabiliyetine bağlıdır. Finansal liberalleşmenin finansal gelişimi sağlamadaki başarısı, daha etkin yatırım dağııımını sağlamasından kaynaklanmaktadır (Williamson ve Mahar, 2002). Gelişmiş ve işlevlerini etkin bir şekilde yerine getiren finansal sistemler, bireysel yatırımcıların sahip olduğu küçük tutarlı mevduatları büyük yatırımlara yönlendirme, yatırımların çeşitlendirilmesine olanak sağlama, tasarruf sahiplerinin katlandığı riski azaltma ve dolayısıyla ekonomik büyümeyi artırma noktasında önem arz etmektedir (Aslan ve Küçükaksoy, 2006, 26).

Finansal gelişme ve ekonomik büyüme arasındaki ilişki Schumpeter'ın (1911) çalışması ile tartışılmaya başlanmış daha sonrasında McKinnon (1973) ve Shaw (1973) konu üzerinde öncü çalışmalara imza atarak tartışmayı devam ettirmiştir. Finansal gelişme-büyüme tartışmasında yaygın olan görüş finansal geliş̧menin ekonomik büyümeyi olumlu etkilediği yönündedir. Bu görüşü savunan diğer yazarlar (Goldsmith, 1969; King ve Levine, 1993; Jayaratne ve Strahan 1996; Levine ve Zervos, 1996; Demirguc-Kunt ve Maksovic 1998; Rajan ve Zingales 1998; Rousseau ve Wachtel, 2000; Arestis, Demetriades ve Luintel, 2001; Beck ve Levine 2004; Ang, 2008) hükümet politikalarının finansal sistemin iyileştirilmesine yönelik oluşturulabileceğini ifade etmektedirler. Böylece finansal gelişmenin büyüme üzerinde önemli bir nedensel etkiye sahip olucağı ileri sürülmektedir. Diğer taraftan ( Lucas, 1988; Stiglitz, 1994; Liang ve Teng, 2006; Ang ve McKibbin, 2007; Odhiambo, 2008) hükümetlerin finansal sistemi geliştirmeye yönelik politikalarının büyüme üzerinde yok denilecek kadar küçük bir etkiye sahip olduğu da iddia edilmektedir. Bu görüşün savunucularından olan Lucas (1988) "ekonomistlerin finansal gelişmenin ekonomik büyüme üzerindeki rolüne aşırı odaklandığını" düşünmektedir. Literatürde yer alan diğer bir görüş ise (Demetrides ve Hussein, 1996; Greenwood ve Smith, 1997) finansal gelişme ve ekonomik büyüme arasında çift taraflı bir nedenselliğin olduğu yönündedir.

Finansal gelişme ve ekonomik büyüme arasındaki ilişkiyi irdelemek üzere yapılan çalışmalar dikkate alındığında bu konuda bir fikir birliğinin olmadığını söylemek mümkündür. Ancak yapılan çalışmalara göre finansal gelişme ve ekonomik büyüme arasındaki ilişkiyi tanımlamak üzere çeşitli yaklaşımlar bulunmaktadır.

Patrick (1966) finansal gelişme ve ekonomik büyüme ilişkisini arz ve talep yönlü olarak tanımlamıştır. Bu yaklaşımlardan ilkini oluşturan arz yönlü yaklaşım finansal gelişmenin ekonomik büyüme üzerinde etkin olduğunu anlatmaktadır. Başka bir deyişle bu yaklaşım finansal sistemin büyüme aşamasında 
olan sektörleri desteklediğini ve sürdürülebilir olmalarına katkıda bulunduğunu iddia etmektedir. Birinci yaklaşımın aksine talep yönlü yaklaşım ekonomik büyümenin finansal gelişmeyi etkilediği yönündedir. Modern finansal kurumlar ve bu kurumların finansal varlıkları ve yükümlülükleri ayrıca finansal hizmetleri reel ekonomideki tasarruf sahiplerinin ve yatırımcıların taleplerine yanıt olarak görülmektedir. Çift yönlü nedenselliği anlatan üçüncü yaklaşım arz ve talep yönlü yaklaşımın birleşimidir ve finansal gelişme ve ekonomik büyüme arasında karşııklı bir nedenselliğin olduğunu ifade etmektedir. Son olarak finansal gelişme ve ekonomik büyüme arasında bir ilişkinin bulunmadığına yönelik yaklaşım dördüncü yaklaşımı oluşturmaktadır.

İlgili literatür incelendiğinde finansal gelişmenin ekonomik büyüme üzerinde kritik bir öneme sahip olduğunu düşünen araştırmacıların çoğunlukta olduğu görülmektedir. Literatürdeki yaygın görüşün aksine, finansal sistemin genişlemesinin Kişi Başına Gelirin artmasından etkilendiğine dair görüşler de mevcuttur. Bu düşünce Robinsons'un (1952) daha fazla finansal kurumun, finansal ürünün ve hizmetin bir ekonomi genişlediğinde finansal hizmetlere olan daha fazla talebe karşılık vermek için ortaya çıkacağını iddia ettiği hipotezine dayanmaktadır. Benzer şekilde güçlü ekonomilerde daha büyük bir finansal hizmet talebi vardır ve bu ekonomilerin daha maliyetli olan bir finansal sisteme gücü yetebilir. Başka bir deyişle reel ekonomik faaliyetlerin seviyesi finansal sistemi ciddi anlamda etkileyebilir (Ang, 2008, 41).

Finansal gelişme ve ekonomik büyümeye ilişkin ilk çalışmaların Schumpeter'a (1912) kadar uzandığı düşünüldüğünde bu konuda çok geniş bir literatürün olduğu tahmin edilebilir. Bu sebeple, bu çalışma kapsamında temel çalışmalara değinmek daha uygun olacaktır. Kendisinden sonraki çalışmalara öncü olan Schumpeter (1912) finansal gelişme kapsamında özellikle iyi işleyen bir bankacılık sisteminin ekonomik gelişmeyi etkileyeceğini belirtmektedir.

Gurley ve Shaw (1955) finansal yapının geliştikçe tasarrufların artabileceğini ve dolayısıyla ekonomik büyüme ile finansal gelişme arasında bir ilişkinin olabileceğini iddia etmektedir. Öncü çalışmalardan birine imza atan Goldsmith (1969) 35 ülkeyi incelemiş ve finansal sistemin büyüklüğü ile ekonomik büyüme arasında pozitif bir ilişki olabileceğini belirtmiştir. Finansal gelişme ve ekonomik büyüme üzerine Goldsmith'i (1969) takiben çalışmalar gerçekleştirilse de konu 1990'larda ampirik çalışmaların artmasıyla yeniden dikkat çekmeye başlamıştır.

Greenwood ve Jovanovich (1990) likit, büyük ve etkin sermaye piyasalarının tasarruf birikim sürecini hızlandırarak büyük yatırımların finansmanına olanak sağladığını ve reel sektörün gelişmesini desteklediğini belirtmektedir.

Levine (1991) finansal gelişme ve ekonomik büyüme ilişkisini "likidite" bazlı değerlendirmiştir. Bu görüşe göre bilgi asimetrisi ve işlem maliyeti likiditeyi engelleyebilir ve likidite riskini yoğunlaştırabilir. Bu sebeple likit finansal piyasalar işlem yapanların daha az maliyete katlandığı ve zamanlamaları açısından daha az belirsizliğe sahip piyasalardır. Likidite ve ekonomik büyüme arasındaki ilişki ise bazı yüksek getirili projelerin uzun dönemli sermaye taahhüdünü gerektirmesinden kaynaklanmaktadır. Ancak yatırımcılar uzun bir süre için kendi yatırımlarının kontrolünü bırakmak istemediğinden eğer finansal sistem uzun vadeli yatırımların likiditesini artıramazsa yatırımların daha az bir kısmı yüksek getirili projelerle sonuçlanabilir ve ekonomi bu durumdan olumsuz etkilenebilmektedir.

King ve Levine (1993) 80 ülkeyi inceledikleri çalışmada finansal gelişmenin ekonomik büyüme üzerinde pozitif ve çok güçlü bir etkisinin olduğu bulgusuna ulaşmış ve geniş yankı uyandırmıştır.

Levine ve Zervos (1998), araştırmalarını 47 ülke için gerçekleştirmiş ve özellikle hisse senedi piyasalarının ve bankacılık sektörünün ekonomik büyüme üzerinde pozitif bir etkiye sahip olduğunu tespit etmiştir.

Beck vd. (2000) dinamik panel dahil olmak üzere birkaç analiz yöntemi kullarak 63 ülkeyi 1960-1995 yılları arası süreçte incelemiş ve finansal aracıların toplam faktör verimliliğini artırdığını ve dolayısıyla büyümeyi pozitif etkilediğini raporlamıştır. Beck, Levine ve Loayza, (2000) finansal aracılık sektörünün ekonomik gidişatın yönünü ve tasarrufların tahsisini etkileyerek değiştirebileceğini iddia etmektedir. Onlara 
göre daha iyi bir finansal aracılık faaliyeti yurtiçi tasarruf oranını artırarak ve yabancı sermayeyi cezbederek büyümeyi etkileyebilir.

Artestis, Demetriades ve Luintel (2002) beş gelişmiş ülkeyi zaman serileri analizi ile incelemiş, bankaların ve hisse senedi piyasalarının ekonomik büyümeyi desteklediğini ancak bankaların daha önemli bir role sahip olduğunu belirtmiştir. Al-Yousif (2002), gelişmekte olan 30 ülkeyi 1970-1999 yılları arası dönem için araştırmıştır. Granger nedensellik testi sonuçlarına göre finansal gelişme ve ekonomik büyüme arasında çift yönlü bir ilişki söz konusudur. Müslümov ve Aras (2002), bir çok çalışmanın sonuçlarına benzer şekilde 22 OECD ülkesi için finansal gelişmenin-sermaye piyasası gelişminin- ekonomik büyümeyi desteklediğini tespit etmiştir.

Achy (2003) finansal sistemin hem potansiyel yatırımcılar arasındaki tasarruf tahsisini geliştirerek hem de tasarruf oranlarını artırarak sermaye birikimini etkilediğini savunmaktadır. Fonlara ulaşım kolaylığı teknolojik inovasyonun finanse edilmesiyle ekonomik büyümeyi etkileyebilmektedir.

Shan ve Jianhong (2006) VAR modeli ile Çin'i inceledikleri çalışmada çift yönlü nedenselliğin varlığına işaret etmektedirler.

Ang ve McKibbin (2007) ise literatürdeki bir çok bulgunun aksine, Malezya için gerçekleştirdikleri çalışmada büyümeden finansal gelişmeye doğru bir nedenselliğin olduğu bulgusuna ulaşmışlardır. Artan (2007) panel veri analizi ile 79 ülkeyi incelediği çalışmasın da literatürdeki bir çok bulgudan farklı olarak özellikle az gelişmiş olan ülkelerde finansal gelişmenin büyümeyi negatif yönde etkilediğini tespit etmiştir.

Ang'a (2008) göre her ekonomi gelişmek için çok yönlü ve etkin bir finansal sisteme ihtiyaç duyar. Bunun nedeni sağlıklı bir finansal sistem ekonominin sağlam temellerinin ayrılmaz bir parçasıdır. Daha etkin bir finansal sistem daha iyi bir finansal hizmet sağlanabileceği anlamına gelir ve bu bir ekonomide Gayri Safi Yurtiçi Hasıladaki büyüme oranının artmasına yol açar. Aksine zayıf bir finansal sistem ekonomi üzerinde olumsuz etkiler yaratır. Yetersiz denetlenen finansal sistem yıkıcı etkilere sahip finansal krizlere eğilimli olabilir.

Anwar ve Nguyen (2009), içsel büyüme literatürüne atıfta bulunarak finansal gelişmenin sermaye birikimi ve teknolojik inovasyon üzerindeki etkisi vasıtasıyla özellikle gelişmekte olan ülkelerdeki uzun dönemli ekonomik büyümede rolünü vurgulamaktadır. Ayrıca finansal yapı ve ekonomik büyüme arasındaki ilişkiyi analiz etmek için banka, piyasa ve hukuk bazlı teorilerin açıklama için alternatifler sunabileceğini belirtmektedir. Örneğin banka bazlı teoriler ticari bankaların ekonomik gelişmedeki pozitif rolünü vurgulamaktadır. Diğer yandan piyasa bazlı teoriler iyi işleyen piyasaların başarıı bir ekonomik performansı teşvik etme avantajlarından bahsetmektedir. Son olarak hukuk ve finans teorisi legal sistemin, hem finansal piyasaların hem de aracıların işini kolaylaştıran legal haklar ve uygulama mekanizmaları ile büyümeyi teşvik eden finansal bir sistem oluşturmadaki rolünü vurgulamaktadır.

Kar, Nazlıoğlu ve Ağır (2011), MENA olarak adlandırılan Orta Doğu ve Kuzey Afrika üklerini panel granger nedensellik testi ile 1980-2007 yılları arası süreç için araştırmış ve finansal gelişme ve ekonomik büyüme arasıdaki nedensellik ilişkisinin değişkenlere göre farklılaştığını ve nedenselliğin yönü hakkında net bir fikir birliğinin olmadığını belirtmiştir.

Ayadi, Arbak, Ben Naceur ve De Groen (2013), Güney ve Kuzey Akdeniz ülkelerini 1985-2009 sürecinde incelemişler ve Özel Sektöre Sağlanan Kredilerle banka mevduat hesaplarının büyümeyi negatif etkilediği sonucuna ulaşmışlardır. Ancak hisse senedi piyasa büyüklüğünün ve likiditesinin büyümede önemli bir rol oynadığını tespit etmişlerdir.

Samargandi, Fidrmuc ve Ghosh (2014) havuzlanmış ortalama grup tahmincisi yöntemini kullanarak 52 orta gelirli ülkeyi 1980-2008 süreci için incelemiş ve finansal gelişmenin ekonomik büyüme üzerinde pozitif ve doğrusal uzun dönemli bir etkisinin olmadığını tespit etmişlerdir.

Finansal gelişme ve ekonomik büyüme ilişkisinin literatürde oldukça geniş bir yer tuttuğu görülmektedir. Literatürdeki çalışmaların bulgularının çoğu finansal gelişmenin ekonomik büyümeyi etkilediği yönündedir. Yapılan çalışmaların birçoğunun ülkeler arası karşılaşmaya dayandığı ve çoğunlukla 
nedensellik ve panel veri analizinin kullanıldığı görülmektedir. Bu çalışma finansal gelişme-ekonomik büyüme ilişkisini son zamanlarda oldukça dikkat çeken "zordaki onlu" ülkeler için incelemesi ile literatüre katkı sağlamaktadır. Zira daha önce zordaki onlu ülkeler üzerine yapılan bir çalışmaya rastlanmamıştır. Ayrıca çalışmadaki analiz döneminin farklılı̆ı literatürdeki finansal gelişme ve ekonomik büyüme çalışmalarına dönemsel bazda katkı sağlamaktadır.

\section{Veri ve Yöntem}

Çalışma finansal gelişme ve ekonomik büyüme arasındaki ilişkinin 1990-2014 dönemi için yıllık veriler kullanılarak zordaki onlu ülkeler üzerine incelenmesini içermektedir. Zordaki onlu ülkelerinden Tayvan'ın verilerine ulaşılamadığı için ülke analize dâhil edilememiştir. Önceki bölümde açıklandığı üzere finansal gelişmişlik ve ekonomik büyüme üzerine farklı veriler kullanılarak birçok çalışma gerçekleştirilmiştir. Araştırmacılar genellikle bankacılık sektörünün toplam büyüklüklerini finansal derinliği ölçmek için kullanmaktadırlar (Levine ve Zervos, 1998, 542). Mevcut literatür incelendiğinde finansal gelişmişlikle ilgili çoğu çalışmada Geniş Para Arzına (M2 ya da M3) ve Özel Sektöre Sağlanan Yurtiçi Kredilere (DCP) yer verildiği görülmektedir. Bu çalışmada Geniş Para Arzı olarak M2 (M1+TL ve YP Vadeli Mevduat) kullanılmıştır. Gayri Safi Sermaye Oluşumu (GCF) da analize dâhil edilmiştir. GCF, kamu ve özel sektör tarafından yapılan yatırımların yıllık büyüme oranını ifade etmektedir. Bu çalışmada literatüre bağlı kalınmış ve finansal gelişmişliğin tespiti için literatürde çoğunlukla tercih edilen değişkenler zordaki onlu ülkeler için analize dâhil edilmiştir. Analizde kullanılan tüm değişkenler Dünya Bankası-World Development Indicators (WDI)- veri tabanından elde edilmiştir. Analizler için Gauss ve Stata programları kullanılmıştır.

Mevcut literatüre göre oluşturulan model aşağıdaki gibidir:

$$
G D P_{i t}=\alpha_{i t}+\beta_{1} D C P_{i t}+\beta_{2} G C F_{i t}+\beta_{3} M 2_{i t}+\varepsilon_{i}
$$

Burada GDP, Kişi Başına Gayri Safi Yurtiçi Hasılayı gösterirken, M2 Geniş Para Arzının, GCF Gayri Safi Sermaye Oluşumunun, DCP Özel Sektöre Sağlanan Yurtiçi Kredilerin Gayri Safi Yurtiçi Hasılaya (GSYH) olan yüzdelerini, $\varepsilon_{i}$ hata terimini ifade etmektedir. GDP değişkeni 2005 yılı baz alınarak elde edilen reel değeri ifade etmektedir.

Panel veri analizinde analizde kullanılacak birim kök ve eş bütünleşme testlerini belirlemek için öncelikle yatay kesit bağımlığının test edilmesi gerekmektedir. Breusch-Pagan (1980) ve Pesaran’a (2004) göre seriler arasında yatay kesit bağımlığı varken bu bağımlılığı dikkate almadan analiz yapmak sonuçları önemli derecede etkilemektedir. Yatay kesit bağımlığını test etmek üzere Breusch-Pagan (1980) tarafından geliştirilen LM testi ve sapması Pesaran vd. (2008) tarafından düzeltilen $L M_{\text {adj }}$ testi de dâhil olmak üzere üç test uygulanmıştır. Testin boş hipotezi HO: "Yatay Kesit Bağımlığı Yoktur" şeklinde tanımlanırken alternatif hipotez H1: "Yatay Kesit Bağımlığı Vardır" olarak tanımlanmaktadır. Yatay kesit bağımlığı hem değişkenler hem de model için test edilebilmektedir. Test LM istatistiğine bağlı olarak tahmin yapmaktadır.

$C D_{L M}=T \sum_{i=1}^{N-1} \sum_{J=i+1}^{N} \rho^{2} i j$

Eşitlik 2'de $\rho^{2} i j$ her bir denklemin EKK ile tahmin edilmesi ile elde edilen kalıntılar arasındaki basit korelasyon katsayısını ve kalıntılar arasında korelasyon olmadığı boş hipotezi altında $C D_{L M}, \mathrm{~N}$ sabitken ve $\mathrm{T} \rightarrow \alpha$ için $\chi^{2}$ dağılımı göstermektedir (Pesaran, 2004: 4). Tablo 1 uygulanan yatay kesit bağımlığı testlerinin sonuçlarını göstermektedir. 
S. Gazel

Tablo 1. Yatay Kesit Bağımlılığı Testleri

\begin{tabular}{|l|c|c|c|c|c|c|c|c|c|c|}
\hline Değişkenler & \multicolumn{2}{|c|}{ GDP } & \multicolumn{2}{c|}{ DCP } & \multicolumn{2}{c|}{ GCF } & \multicolumn{2}{c|}{ M2 } & \multicolumn{2}{c|}{$\begin{array}{c}\text { Eşbütünleşme } \\
\text { Denklemi }\end{array}$} \\
\hline Testler & test ist. & p değeri & test ist. & p değeri & test ist. & p değeri & test ist. & p değeri & test ist. & p değeri \\
\hline $\begin{array}{l}\text { LM (Breusch ve } \\
\text { Pagan, 1980) }\end{array}$ & 45.8 & 0.12 & 57.8 & 0.01 & 110 & 0.00 & 71.7 & 0.00 & 166.5 & 0.00 \\
\hline $\begin{array}{l}\text { CDLM (Pesaran } \\
2004)\end{array}$ & -2.41 & 0.00 & -2.68 & 0.00 & -3.12 & 0.00 & -2.48 & 0.00 & 5.10 & 0.00 \\
\hline $\begin{array}{l}\text { LM } \\
2008)\end{array}$ & 11.5 & 0.00 & 6.77 & 0.00 & 4.63 & 0.00 & 3.47 & 0.00 & 10.82 & 0.00 \\
\hline
\end{tabular}

Tablo 1'deki sonuçlara göre olasılık değerleri 0.05 'ten küçük olduğu için boş hipotez istatistiki olarak anlamlı şekilde reddedilir. Başka bir ifade ile değişkenler ve model için yapılan yatay kesit bağımlıık testleri (GDP değişkeni için LM testi hariç olmak üzere) yatay kesit bağımlılı̆ıının hem değişkenlerde hem de modelde var olduğunu göstermektedir. Bu durumda paneli oluşturan ülkeler arasında yatay kesit bağımlığının olduğunu ve dolayısıyla ülkelerin birinde finansal gelişmişliğe (Özel Sektöre Sağlanan Yurtiçi Krediler, Gayri Safi Sermaye Oluşumu ve M2) ilişkin değişkenlerde meydana gelen şokun diğer ülkeleri de etkilediğini söylemek mümkündür. Bu nedenle bu ülkelerin politikalarını şekillendirirken diğer ülkelere ilişin para arzı, Gayri Safi Sermaye Oluşumu ve Özel Sektöre Sağlanan Kredileri de dikkate almaları gerekmektedir.

Panel Veri Analizinde eğim katsayılarının homojenliğinin test edilmesi gerekmektedir. Nitekim homojenliğe ilişkin sonuçlar hem daha sonra uygulanacak analiz yöntemlerinin seçimine yardımcı olacak hem de daha gerçekçi yorumlamalar yapılmasını sağlayacaktır. Pesaran ve Yamagata (2008) yatay kesitlerin eğim parametrelerinin homojen olup olmadığını tespit etmek üzere Swamy (1970) tarafından ortaya konulan testi geliştirmişlerdir. Delta Testinin boş hipotezi "Eğim Katsayılarının Homojen" olduğunu ifade etmektedir. Eşbütünleşme katsayılarının homojen olup olmadığına ilişkin sonuçlar Tablo 2'de yer almaktadır.

Tablo 2. Eş Bütünleşme Katsayılarının Homojenliğinin Test Edilmesi

\begin{tabular}{|c|c|c|}
\hline & Test İstatistiği & Olasılık Değeri \\
\hline$\Delta$ & 8.097 & 0.000 \\
\hline$\Delta$ adj & 9.010 & 0.000 \\
\hline
\end{tabular}

Tablo 2' de hesaplanan testlerin olasılık değerleri 0.05'ten küçük olduğu için HO hipotezi reddedilmiş ve eşbütünleşme denklemlerindeki eğim katsayılarının homojen olmadığına karar verilmiştir.

Serilerde yatay kesit bağımlılığının tespit edilmesi analizin bundan sonraki aşamalarının yatay kesit bağımlığına göre gerçekleştirilmesini gerektirmektedir. Örneğin panel veride yatay kesit bağımlığının olması ikinci nesil birim kök testlerinin kullanılmasının doğru olduğunu ifade etmektedir. Zira yatay kesit bağımlı̆ı varken birinci nesil birim kök testleri sapmalı sonuçlar verebilmektedir. Aynı şekilde seriler arasında eşbütünleşmenin varlığının tespit edilmesi ve sonrasında eşbütünleşme denkleminin tahmin edilmesi yatay kesit bağımlılı̆ı dikkate alınarak gerçekleştirilmelidir. Her bir yatay kesitin hata terimlerinin bağımsız olduğunu ve yatay kesitlerin açıklayıcı değişkenlerden eşit derecede etkilendiğini varsayan birinci nesil birim 
kök testleri, kesitlerin birbiri ile bağıntısını dikkate alan ikinci nesil birim kök testlerine göre genellikle daha az gerçekçi bulunmaktadır. Literatürde sıklıkla başvurulan ikinci nesil birim kök testlerine SURADF (Breuer, Mcknown ve Wallace, 2002), CADF (Pesaran, 2007), PANKPSS (Carrion-Silvestre vd. 2005) ve Hadri ve Kurozimi (2012) örnek olarak verilebilir.

Bu çalışmada birim kökün varlığını tespit etmek üzere Pesaran (2007) tarafından geliştirilen CADF testi kullanılmıştır. CADF testi aşağıdaki denklemi tahmin etmektedir.

$\Delta y_{i t}=a_{i}+k_{i} y_{i, t-1}+l_{i} \overline{y_{t-1}}+m_{i} \Delta \overline{y_{t}}+\varepsilon_{i t}$

Boş hipotez "serinin durağan olmadığını", alternatif hipotez ise "serinin durağanlığıı" ifade eder. Birim kökle ilgili panelin geneline ilişkin bir değerlendirme yapabilmek için CIPS (Cross-Sectionally Augmented IPS) istatistiği kullanılabilir. CIPS istatistiği denklem (4)'teki gibi hesaplanmaktadır:

$\operatorname{CIPS}(\mathrm{N}, \mathrm{T})=\mathrm{t}-\mathrm{bar}=N^{-1} \sum_{i=1}^{N} t_{i}(N, T)$

Paneli oluşturan her bir ülke için birim kök istatistikleri (CADF) ve panelin genelini değerlendirmek amacı ile kullanılan CIPS istatistikleri Tablo 3'te yer almaktadır.

Tablo 3. CADF Birim Kök Testi Sonuçları

\begin{tabular}{|c|c|c|c|c|c|c|c|c|c|c|c|c|c|c|c|c|}
\hline \multirow[b]{2}{*}{ Ülke } & \multicolumn{2}{|c|}{ GDP } & \multicolumn{2}{|c|}{$\Delta G D P$} & \multicolumn{2}{|c|}{ DCP } & \multicolumn{2}{|c|}{$\triangle \mathrm{DCP}$} & \multicolumn{2}{|c|}{ GCF } & \multicolumn{2}{|c|}{$\Delta \mathrm{GCF}$} & \multicolumn{2}{|c|}{ M2 } & \multicolumn{2}{|c|}{$\Delta \mathrm{M} 2$} \\
\hline & CADF & $p$ & CADF & $\mathrm{p}$ & CADF & $\mathrm{p}$ & CADF & $\mathrm{p}$ & CADF & $p$ & CADF & $p$ & CADF & $p$ & CADF & $p$ \\
\hline Brezilya & -1.34 & 2 & -2.46 & 2 & $-3.75^{* *}$ & 5 & -1.98 & 4 & -2.89 & 2 & -2.02 & 4 & -1.34 & 3 & $-4.35^{* *}$ & 3 \\
\hline Rusya & $\mid-3.82^{* *}$ & 3 & -2.46 & 2 & -0.97 & 2 & $-3.70^{* *}$ & 4 & -2.88 & 4 & $-3.90^{* *}$ & 2 & -0.92 & 2 & -1.43 & 3 \\
\hline Şili & $-3.39 *$ & 2 & -2.88 & 2 & -1.44 & 2 & $-3.18^{* *}$ & 2 & -1.79 & 2 & -2.26 & 3 & -1.85 & 2 & -2.16 & 2 \\
\hline Kolambiya & 0.88 & 2 & -2.00 & 2 & -1.75 & 2 & -2.42 & 3 & -2.46 & 4 & $-3.67^{* *}$ & 2 & -0.36 & 3 & -2.21 & 3 \\
\hline Peru & -1.31 & 2 & $-3.14^{*}$ & 2 & -2.20 & 5 & -1.95 & 3 & -0.99 & 2 & $-4.34^{* *}$ & 2 & -1.88 & 2 & -2.58 & 2 \\
\hline Singapur & $-4.06^{* *}$ & 2 & $-4.12^{* *}$ & 2 & -1.44 & 2 & -2.38 & 2 & -2.15 & 2 & -2.74 & 2 & $-3.09^{* *}$ & 4 & $-5.55^{* * *}$ & 2 \\
\hline Güney Afrika & -2.68 & 2 & $-4.22^{* *}$ & 2 & -2.18 & 2 & -2.69 & 5 & -1.88 & 2 & $-5.16^{* * *}$ & 2 & -2.21 & 2 & -2.48 & 2 \\
\hline Tayland & -2.77 & 2 & $-3.08^{*}$ & 2 & -1.99 & 2 & -2.12 & 2 & -1.05 & 2 & $-3.08^{*}$ & 2 & -1.82 & 2 & -2.61 & 2 \\
\hline Güney Kore & -0.89 & 2 & $-3.23^{*}$ & 2 & -1.19 & 2 & -2.83 & 2 & $-3.32^{* *}$ & 2 & $-4.76^{* * *}$ & 2 & -0.26 & 5 & -1.00 & 5 \\
\hline CIPS & -2.1 & & -3.07 & & -1.8 & & -2.5 & & -2 & & $-3.55^{* * *}$ & & 1.53 & & $-2.71^{* * *}$ & \\
\hline
\end{tabular}

Ülkeler ve panelin geneli için kritik değerler Pesaran’ın (2007) çalışmasından elde edilmiştir. Ülkeler için kritik değerler \%1, \%5 ve \%10 için sırasıyla $-4.35,-3.43,-3.00$ iken panelin geneli için kritik değerler \%1, \%5 ve \%10 için sırasıyla; $-2.60,-2.34,-2.21$ 'dir. Değerlendirmede \%1 ve \%5'lik kritik değerler kullanılmıştır. ${ }^{* * *},{ }^{* *},{ }^{*}$ sırasıyla \%1, \%5 ve \%10 seviyelerinde anlamlılığı göstermektedir. Fark operatörü $(\Delta)$ değişkenin farkını göstermektedir. Tabloda $p$ ile gösterilen sütunlar gecikme uzunluklarını göstermektedir. Tüm değişkenler için sabitli model seçilmiştir.

Birim kök testi sonuçlarının yer aldığı Tablo 3 incelendiğinde panelin genelini değerlendirebileceğimiz CIPS istatistiği, verilerin seviyede durağan olmayıp birinci farkları alındığında durağan olduklarını göstermektedir. Bu sonuçlar analize konu olan verilerin aynı düzeyde bütünleşik [ı(1)] olduklarını ifade etmektedir. 
Netice itibariyle panel veride eşbütünleşme olup olmadığı test edilirken yatay kesit bağımlığını dikkate alan testlerin kullanılması uygun olacaktır. Ayrıca yatay kesit eğim parametrelerinin heterojenliğinin de dikkate alınması gerekmektedir. Çalışmadaki panel verinin yatay kesit bağımlıı̆ı, heterojenlik ve birim kök testi sonuçları göz önünde bulundurulduğunda Westerlund (2008) tarafından ortaya konulan DurbinHausman Eşbütünleşme Testi uygun görünmektedir. Durbin-Hausman Eşbütünleşme Testinde eşbütünleşme ilişkisi panel için ve paneli oluşturan gruplar için ayrı ayrı tespit edilebilmektedir. Panel testinde otoregresif parametrelerin sektörler arasında değişmediği varsayılırken grup testinde katsayıların sektörler arasında farklılaşmasına izin verilmektedir. Panel testi "eşbütünleşme yoktur" boş hipotezini test etmektedir. Boş hipotezin reddi panelin tümü için eş bütünleşme olduğunu ifade eder. Grup testinin boş hipotezi "eşbütünleşme yoktur" ve alternatif hipotez "en az bir kesitte eşbütünleşme vardır" şeklinde tanımlanmakta ve boş hipotezin reddi bazı sektörlerde eşbütünleşme ilişkisinin var olduğunu anlatmaktadır.

Tablo 4. Durbin Hausman Eşbütünleşme Testi Sonuçları

\begin{tabular}{|l|l|l|}
\hline & İstatistik Değeri & p değeri \\
\hline Durbin-H Grup İstatistiği & 33.260 & 0.000 \\
\hline Durbin-H Panel İstatistiği & 17.604 & 0.000 \\
\hline
\end{tabular}

Tablo 4 incelendiğinde Durbin Hausman testi sonuçları hem grup hem de panel istatistiğinin olasılık değerlerinin 0.05 'ten küçük olduğu göstermektedir. Bu durumda $\mathrm{HO}$ hipotezi reddedilmiş ve dolayısıyla hem panelin bütünü için hem de kesitler için eşbütünleşme ilişkisinin var olduğu tespit edilmiştir. Başka bir ifade ile panelin geneli ve paneli oluşturan kesitler için Kişi Başına Gayri Safi Yurtiçi Hasıla, Geniş Para Arzı, Gayri Safi Sermaye Oluşumu ve Özel Sektöre Sağlanan Yurtiçi Krediler serileri arasında eşbütünleşme ilişkisinin var olduğuna karar verilmiştir. Bütün bu analizler sonucunda uzun ve kısa dönem katsayılarının tahminine geçilebilir.

Panel dinamik en küçük kareler yöntemi gibi metotlar sadece uzun dönem parametrelerini tahmin etmek için geliştirilmiştir. Oysa uzun dönem parametrelerinin yanında kısa dönem parametrelerinin tahmini de önemlidir. Havuzlanmış Ortalama Grup Tahmincisi (PMGE), Ortalama Grup Tahmincisi (MGE) ve Dinamik Sabit Etkiler Tahmincisi (DFE), hata düzeltme modeli oluşturarak hem kısa dönemli hem uzun dönmeli parametreleri birlikte tahmin etmektedir. Dinamik Sabit Etkiler Tahmincisi hata düzeltme modelini sabit etkiler varsayımıyla tahmin etmekte, tüm parametreleri sabit tuttuğu için birimlere göre hesaplamalar yapmaktadır. Hata Düzeltme Modeli (Tatoğlu, 2013);

$Y_{i t}=\phi_{i} Y_{i t-1}+\beta_{i}^{\prime} X_{i t}+\sum_{j=1}^{p-1} \lambda_{i j} \Delta Y_{i t-j}+\sum_{j=0}^{q-1} \delta_{i j} \Delta X_{i t-j}+\varepsilon_{i t}$

Burada $\phi_{i}$ hata düzeltme parametresini ifade eder. Ayrıca,

$\phi_{i}=-\left(1-\sum_{j=1}^{p} \lambda_{i j}\right), \beta_{i}=\sum_{j=0}^{q} \delta_{i j}, \lambda_{i j}^{*}=-\sum_{m=j+1}^{p} \lambda_{i m}, \delta_{i j}^{*}=-\sum_{m=j+1}^{q} \delta_{i m}$

Yukarıdaki eşitliklerde $\phi_{i}$, anlamlı ve negatif ise $Y_{i t}$ ile $X_{i t}$ arasında uzun dönemli ilişkinin olduğunu göstermektedir.

Çalışmada panel hata düzeltme modeli dinamik sabit etkiler tahmincisi ile tahmin edilmiştir. Sonuçlar Tablo 5'te yer almaktadır. Hata düzeltme parametresinin negatif ve anlamlı olması Özel Sektöre Sağlanan Yurtiçi Krediler, Gayri Safi Sermaye Oluşumu ve Geniş Para Arzı değişkenleri arasında analize dâhil edilen ülkeler bazında teorik olarak uzun dönemli çok zayıf bir ilişkinin varlığını ifade etse de katsayı uzun dönemli ilişkinin olmadığı şeklinde yorumlanabilecek kadar küçük bir değerdir. Zira hata düzeltme katsayısı bir dönemde oluşan dengesizliklerin ancak çok az bir kısmının (\% .02) bir sonraki dönemde düzelecek ve uzun dönem dengesine yaklaşma sağlanacağını göstermektedir. Bu durum uzun dönemli bir ilişkinin 
olmadığı şeklinde yorumlanabilir. Değişkenlerin uzun dönem katsayıları anlamlı olmadığı için uzun dönemde değişkenler arası ilişkileri yorumlamak mümkün görünmemektedir.

Tablo 5. Eşbütünleşme Katsayılarının Tahmini

\begin{tabular}{|c|c|c|c|c|}
\hline Açıklayıcı Değişkenler & Katsayı & $\begin{array}{c}\text { Standart } \\
\text { Hata }\end{array}$ & z değeri & p değeri \\
\hline & \multicolumn{4}{|c|}{ Kısa Dönem Katsayıları } \\
\hline DCP & .04600 & .0219 & 2.09 & 0.03 \\
\hline GCF & .18251 & .0197 & 9.26 & 0.00 \\
\hline M2 & -.0009 & .0003 & -2.54 & 0.01 \\
\hline CONS. & .06730 & .0173 & 3.87 & 0.00 \\
\hline DCP & 66.37 & 74.82 & -1.36 & 0.17 \\
\hline GCF & -365.8 & 269.7 & 0.89 & 0.37 \\
\hline M2 & -59.48 & 101.6 & -0.59 & 0.55 \\
\hline EC & -.0002 & .0000 & -2.28 & 0.02 \\
\hline
\end{tabular}

Tablo 5'te kısa dönem katsayılarına bakıldığında katsayıların \%1 veya \%5 seviyelerinde anlamlı olduğu görülmektedir. Özel Sektöre Sağlanan Yurtiçi Kredilerin ve Gayri safi Sermaye Oluşumunun katsayısının işareti pozitiftir. Bu durumda Özel Sektöre Sağlanan Yurtiçi Kredilerdeki \%1'lik artı̧̧ kısa dönemde Kişi Başına Gayrisafi Yurtiçi Hasılayı \%0.04 artırırken, Gayri Safi Sermaye Oluşumundaki \%1'lik artış \%0.18 artırmaktadır. Geniş Para Arzının katsayısının işaretinin negatif olduğu ancak katsayının oldukça düşük olduğu (.0009) dikkat çekmektedir. Bu durumda açıklayıcı değişkenlerin çoğu kısa dönemde finansal gelişme ve ekonomik büyüme arasında pozitif bir ilişki olduğunu ifade etmektedir. Başka bir deyişle zordaki onlu ülkeler için kısa dönemde finansal gelişmenin ekonomik büyümeyi olumlu etkilediğini söylemek mümkündür.

Bu çalışmada uzun dönemli ilişkiye odaklanabilmek amacıyla uzun dönem eşbütünleşme katsayıları Ortak ilişkili Etkiler Ortalama Grup (CCEMG) yöntemiyle de tahmin edilmiştir ve sonuçlar karşılaştırılmıştır. Pesaran (2006), yatay kesit bağımlıığını göz önünde bulundurarak uzun dönem ilişkisini tespit edebilmek için Ortak illişkili Etkiler (Common Correlated Effects (CCE)) tahmincilerini geliştirmiştir. Bunlar, Ortak ilişsili Etkiler Ortalama Grup (Common Correlated Effects Mean Group (CCEMG)) tahmincisi ve Ortak ílişkili Etkiler Havuzlanmış (Common Correlated Effects Pooled (CCEP)) tahmincisidir. CCE tahmincileri, bağımsız değişkenlerin durağan olması (I(0)) ya da birinci dereceden eşbütünleşik (I(1)) olduğu durumlarda tutarlı sonuçlar vermektedir.

CCE yöntemi Eşitlik 7'deki panel veri regresyon modeline dayanmaktadır:

$y_{i t}=a_{\imath} d_{t}+\widehat{b}_{\imath} x_{i t}+e_{i t}$

$e_{i t}=y f_{t}+\varepsilon_{i t}$

Denklemde gözlenebilen (Sabit, trend, mevsimsel kuklalar vb.) ve gözlenemeyen ortak etkileri sırasıyla $d$ ve $f$ temsil etmektedir. Tablo 6 'da tahmin sonuçları yer almaktadır. 
S. Gazel

Tablo 6. CCEMG Tahmin Sonuçları

\begin{tabular}{|c|c|c|c|}
\hline & Katsayılar & Standart Sapma & t- İstatistiği \\
\hline DCP & 0.015 & 0.033 & 0.449 \\
\hline GCF & $0.142^{* * *}$ & 0.047 & 2.974 \\
\hline M2 & 0.121 & 0.085 & 1.426 \\
\hline
\end{tabular}

Tablo 6'daki sonuçlar incelendiğinde Özel Sektöre Sağlanan Yurtiçi Krediler ve M2 değişkenleri için uzun dönem eşbütünleşme katsayılarının anlamlı olmadığı, Gayri Safi Sermaye Oluşumu değişkenine ilişkin katsayının ise anlamlı olduğu gözlenmektedir. Analiz sonuçları Dinamik Sabit Etkiler tahmincisi ile gerçekleştirilen analizin sonuçlarıyla benzerlik göstermektedir. Zira katsayıların çoğu bu analiz için de anlamsızdır. Her iki analiz sonuçları değerlendirildiğinde, hem hata düzeltme katsayısı hem de değişkenlere ilişkin katsayılar zordaki onlu ülkeleri için uzun dönemde bir ilişkinin varlığına işaret etmemektedir.

\section{Sonuç ve Değerlendirme}

Bir ülkenin refah göstergelerinden biri olarak kabul edilen ekonomik büyüme, Gayri Safi Yurtiçi Hasılayla ya da GSYiH'nın Kişi Başına Reel değerleri ile ölçülmektedir. Ekonomik büyümeyi birçok faktörün etkilediği aşikârdır ancak bu faktörler içerisinde finansal gelişmişliğin bir rolünün olup olmadığı literatürde uzunca bir süredir tartışılmaktadır. Incelenen dönem ve yönteme göre finansal gelişme ve ekonomik büyüme ilişkisine dair sonuçların farklılaştığı düşünüldüğünde konuya ilişkin tartışmaların devam etme eğiliminde olduğu söylenebilir. Bu çalışma finansal gelişme ve ekonomik büyüme arasındaki ilişkinin Brezilya, Kolombiya, Şili, Güney Afrika, Güney Kore, Peru, Rusya, Tayland, Singapur ve Tayvan için 19902014 sürecinde incelenmesini içermektedir. Çalışmada uzun dönemli ilişkiyi tespit edebilmek için hem Ortak İlişkili Etkiler Ortalama Grup yöntemine hem de Dinamik Sabit Etkiler Tahmincisine yer verilmiştir. Çalışmada uzun dönem parametreleri ile birlikte kısa dönem parametrelerine de yer verilmiştir.

Analiz sonuçları finansal gelişme ve ekonomik büyüme arasındaki ilişinin Brezilya, Kolombiya, Şili, Güney Afrika, Güney Kore, Peru, Rusya, Tayland, Singapur ve Tayvan ülkeleri için kısa ve uzun dönem için farklılaştığını göstermektedir. Uzun dönemde, finansal gelişme ve ekonomik büyüme arasında teorik olarak oldukça zayıf bir ilişkinin varlığını ifade eden bir katsayı elde edilmiş olsa da katsayı uzun dönemli bir ilişkinin olmadığı şeklinde yorumlanabilir. Zira bu durum değişkenlerin katsayılarında da ortaya çıkmış ve değişkenler için anlamlı sonuçlar elde edilememiş dolayısıyla incelenen veriler kapsamında bir kıyaslama yapılamamıştır. Analizde uzun dönemli ilişkiye daha fazla odaklanmak için yatay kesit bağımlılı̆ıını göz önünde bulunduran Ortak İlişkili Etkiler Ortalama Grup (CCEMG) yöntemine de yer verilmiştir. Analiz sonuçları katsayıların çoğunun uzun dönemli ilişkinin varlığı için anlamlı olmadı̆̆ını göstermektedir. Sonuçlar Dinamik Sabit Etkiler yöntemi ile tespit edilen bulgularla benzerlik göstermektedir. Ancak Dinamik Sabit Etkiler tahmincisiyle kısa dönemde bütün değişkenlerin katsayılarının yüksek bir anlamlılığa sahip olduğu görülmüştür. Özel Sektöre Sağlanan Kredilerin ve Gayri Safi Sermaye Oluşumunun kısa vadede ekonomik büyümeyi pozitif yönde etkilediği tespit edilmiştir. Başka bir ifade ile kısa dönemde zayıf bir pozitif ilişkinin varlığından söz etmek mümkündür. Bu sonuçlar literatürde yaygın olan "finansal gelişme ve ekonomik büyüme arasında pozitif bir ilişkinin" olduğu bulguları ile örtüşmektedir. Finansal gelişmişliğe iliş̧in birçok değişkenin kullanılabileceği göz önünde bulundurulduğunda zordaki onlu ülkeler için yapılan bu analiz değişkenler farklılaştırılarak ya da analiz dönemi değiştirilerek incelenebilir. 


\section{Kaynaklar}

Achy, L. (2004). Financial Liberalization, Saving, Investment and Growht in MENA Countries. Middile East Economics, 6, 67-94.

Al-Yousif, Y. K. (2002). Financial Development and Economic Growth Another Look at the Evidence from Developing Countries. Review of Financial Economics, 11, 131-150.

Ang, J.B. (2008). What are the Mechanisms Linking Financial Development and Economic Growth in Malysia?. Economic Modelling, 25(1), 38-53.

Akel, Veli. (2015). Kırılgan Beşli Ülkelerinin Hisse Senedi Piyasaları Arasındaki Eşbütünleşme Analizi, Uluslararası Yönetim iktisat ve İşletme Dergisi, Cilt 11, Sayı 24.

Ang, J. B. \& McKibbin, W. J. (2007). Financial Liberalization, Financail Sector Development and Growth: Evidence from Malaysia. Journal of Development Economics, 84(1), 215-233.

Anwar, S. (2009). Financial Development and Economic Growth in Vietnam. Journal of Economics and Finance, 35(3), 348-360.

Artan, S. (2007). Finansal Kalkınmanın Büyümeye Etkileri: Literatür ve Uygulama. iktisat, İşletme ve Finans, 22, 70-89.

Artestis, P, Demetriades, P., \& Luintel, K.B. (2002). Financial Development and Economic Growth: The Role of Stock Markets. Journal of Money, Credit and Banking, 33(1), 16-41.

Aslan, Ö. \& Küçükaksoy, i̇. (2006). Finansal Gelişme ve Ekonomik Büyüme İlişkisi: Türkiye Ekonomisi Üzerine Ekonometrik Bir Uygulama. Ekonometri ve Istatistik, 4, 12-28.

Ayadi, R., Arbak, E., Ben-Naceur, S., \& De Groen, W.P. (2013). Financial Development, Bank Efficiency and Economic Growth across the Mediterranean. MEDPRO Technical Report, 30, Mart

Beck, T., Levine, R. \& Loayza, N. (2000). Finance and the Sources of Growth. Journal of Financial Economics, 58(1-2), 261-300.

Beck, T., \& Levine, R. (2004). Stock Markets, Banks, and Growth: Panel Evidence. Journal of Banking and Finance, 28, 423-442.

Breusch, T. S., \& Pagan, A.R. (1980). The Lagrange Multiplier Test and Its Applications to Model Specification in Econometrics. Review of Economic Studies, 47(1), 239-253.

Demetriades, P., \& Hussein, K. (1996). Financial Development and Economic Growth, Cointegration and Causality Tests for 16 Countries. Journal of Development Economics, 51(2), 387-411.

Demirgüç-Kunt, A., \& Maksimovic, V. (1998). Law, Finance and Firm Growth. Journal of Finance, 53(6), $2107-2137$.

Dornbusch, R., \& Fischer, S. (1998). Makroekonomi. (Çev. S. Ak, M. Fisunoğlu, E. Yıldırım \& R. Yıldırım). İstanbul, McGraw-Hill- Akademi.

Goldsmith, R. W. (1969). Financial Structure and Development. New Haven, CT: Yale University Press.

Gül, E., \& Ergün, H. (2012). Gelişmiş ve Azgelişmiş Ülkelerde Ekonomik Büyüme Dinamikleri: Bir Panel Veri Analizi. Uluslararası Alanya İşletme Fakültesi Dergisi, 4(1), 127-136.

Greenwood, J., \& Smith, B.D. (1997). Financial Markets in Development and the Developmnet of Financial Markets. Journal of Economic Dynamics and Control, 21(1), 145-181.

Greenwood, J., \& Jovanovic, B. (1990). Financial Development, Growth, and the Distribution of Income. Journal of Political Economy, 98(5), 1076-1107.

Jayaratne, J., \& Strahan, P.E. (1996). The Finance-Growth Nexus: Evidence From Bank Branch Deregulation. The Quarterly Journal of Economics, August, 639-670.

Kar, M., Nazlıoğlu, Ş., \& Ağır, H. (2011). Financial Development and Economic Growth Nexus in the MENA Countries: Bootstrap Panel Granger Causality Analysis. Economic Modelling, 28, 685-693.

King, R.G., \& Levine, R. (1993). Finance and Growth: Schumpeter Might Be Right. Economic Journal , 107, 771-782

Levine, R., \& Zervos, S. (1998). Stock Market, Banks and Economic Greowth. American Economic Review, 88, $537-558$.

Levine, R. (1997). Financial Development and Economic Growth: Views and Agenda. Journal of Economic Literature, 35 (2), 688-726.

Levine, R. (1991). Stock Markets, Growth and Tax Policy. Journal of Finance, 46(4), 1445-65.

Liang, Q., \& Teng, J. Z. (2006). Financial Development and Economic Growth: Evidence from Chine. China Economic Review, 17(4), 395-411. 
Lucas, R. E. (1988). On the Mechanics of Economic Development. Journal of Monetary Economics, 22, 3-42.

McKinnon, R.I. (1973). Money and Capital in Economic Develepment. DC: The Brookings Institution.

Müslümov, A., \& Aras, G. (2002). Sermaye Piyasası Gelişmesi ve Ekonomik Büyüme Arasındaki Nedensellik İlişkisi: OECD Ülkeleri Örneği. iktisat, İşletme ve Finans, 17, 90-100.

Shaw, E.S. (1973). Financial Deepening in Economic Development. New York: Oxford University Press.

Schumpeter, J.A. (1912). The Theory of Economic Development, Cambridge: Harward University Press.

Odhiambo, N. M. (2008). Financial Depth, Savings and Economic Growth in Kenya: A Dynamic Causal Linkage. Economic Modelling, 25(4), 704-713.

Patrick, H.T. (1966). Financial Development and Economic Growth in Underdeveloped Countries. Economic Develeopment and Cultural Change, 14, 174-189.

Pesaran, M.H. (2004). General Diagnostic Tests for Cross Section Dependence in Panels. CESifo Working Paper Series No. 1229; IZA Discussion Paper No. 1240.

Peseran, M.H. (2006). A Simple Panel Unit Root Test in the Presence of Crosssection Dependecy. Cambridge Working Papers in Economics, 0346.

Pesaran, M.H., \& Yamagata, T., (2008). Testing Slope Homogeneity in Large Panels. Journal of Econometrics, 142, 5093.

Pesaran, Hashem, M. (2007). A Simple Panel Unit Root Test in the Presence of Cross Section Dependence. Journal of Applied Econometrics, 22(2), 265-312.

Rausseau, P. L., \& Watchel (1998). Financial Intermediation and Economic Performance Historical Evidence From Five Industrialized Countries. Journal of Money Credit and Banking. 30(4), 865-867.

Rajan, R. G., \& Zingales, L. (1998). Financial Dependence and Growth. American Economic Review, 88, 559-586.

Samargandi, N., Fidrmuc, N., \& Ghosh, S.(2014). Is the Relationship Between Financial Development and Economic Growth Monotonic? Evidence from a Sample of Middle Income Countries. CESifo Working Paper, 4743

Shan, J., \& Jianhong, Q. (2006). Does Financial Development 'lead' Economic Growth? The case of China. Annals of Economics and Finance, 1, 232-250.

Stiglitz, J. E. (1994). The Role of the State in Financial Markets, World Bank Annual Conferance on Development Economics.

Tatoğlu, F. Y. (2013). Ileri Panel Veri Analizi. Beta Yayıncılık,

Todaro, M. P. \& Smith, S. (2012). Economic Development, 11th Edition, Pearson.

Williamson, J., \& Zagha, R. (2002). From Slow Growth to Slow Reform. Paper presented to the Third Annual Stanford Economic Conference on Indian Economic Reform.

Worrachate, A., \& Xie, Y. (2015). Morgan Stanley's Fragile Five Swells to Troubled 10 in Selloff, Bloomberg Business. Erişim Adresi: http://www.bloomberg.com/news/articles/2015-08-16/morgan-stanley-s-fragile-five-swells-totroubled-10-in-selloff 


\section{Ekler}

\section{1. Çalışmada Kullanılan Kişi Başına Gayri Safi Yurtiçi Hasıla Verisi}

\begin{tabular}{|c|c|c|c|c|c|c|c|c|c|}
\hline & BRA & RUS & $\mathrm{CHL}$ & $\mathrm{COL}$ & PER & SGP & ZAF & THA & KOR \\
\hline 1990 & 4001.541 & 5685.159 & 4121.338 & 2833.358 & 1903.473 & 16553.52 & 5068.049 & 1571.572 & 8829.135 \\
\hline 1991 & 3995.161 & 5386.174 & 4369.603 & 2842.38 & 1907.06 & 17164.75 & 4914.095 & 1688.123 & 9591.294 \\
\hline 1992 & 3913.632 & 4601.492 & 4816.612 & 2929.28 & 1860.219 & 17837.4 & 4709.776 & 1809.497 & 10039.39 \\
\hline 1993 & 4033.253 & 4207.392 & 5060.121 & 2943.106 & 1921.109 & 19398.21 & 4668.246 & 1945.016 & 10566.93 \\
\hline 1994 & 4183.876 & 3683.096 & 5256.193 & 3058.055 & 2118.136 & 20853.58 & 4715.77 & 2104.541 & 11378.78 \\
\hline 1995 & 4302.34 & 3529.541 & 5720.017 & 3159.228 & 2234.458 & 21651.09 & 4757.962 & 2279.74 & 12270.89 \\
\hline 1996 & 4329.66 & 3407.431 & 6050.951 & 3166.837 & 2256.775 & 22354.55 & 4853.348 & 2390.84 & 13027.94 \\
\hline 1997 & 4408.433 & 3460.851 & 6359.509 & 3217.979 & 2361.855 & 23408.92 & 4866.889 & 2332.798 & 13650.62 \\
\hline 1998 & 4357.59 & 3282.855 & 6477.886 & 3180.37 & 2313.688 & 22123.38 & 4777.567 & 2063.761 & 12778.07 \\
\hline 1999 & 4314.449 & 3503.785 & 6347.269 & 2994.945 & 2311.171 & 23285.07 & 4775.54 & 2130.361 & 14049.01 \\
\hline 2000 & 4439.071 & 3870.407 & 6551.573 & 3075.286 & 2337.968 & 24921.24 & 4854.366 & 2205.774 & 15162.4 \\
\hline 2001 & 4433.268 & 4084.776 & 6690.886 & 3075.952 & 2319.205 & 24027.15 & 4884.444 & 2227.648 & 15731.67 \\
\hline 2002 & 4507.663 & 4298.274 & 6757.99 & 3102.663 & 2412.975 & 24811.25 & 4994.39 & 2319.305 & 16806.93 \\
\hline 2003 & 4503.575 & 4632.842 & 6948.026 & 3173.74 & 2481.588 & 26297.1 & 5076.95 & 2458.297 & 17214.2 \\
\hline 2004 & 4700.133 & 4985.324 & 7289.118 & 3291.463 & 2573.218 & 28449.42 & 5239.949 & 2590.191 & 17989.97 \\
\hline 2005 & 4792.604 & 5323.466 & 7614.522 & 3393.993 & 2703.437 & 29869.63 & 5444.076 & 2689.951 & 18657.52 \\
\hline 2006 & 4931.504 & 5776.388 & 7869.604 & 3567.009 & 2875.093 & 31514.37 & 5671.153 & 2813.025 & 19528.39 \\
\hline 2007 & 5176.43 & 6280.138 & 8194.139 & 3756.854 & 3087.216 & 32982.98 & 5893.514 & 2946.294 & 20499.65 \\
\hline 2008 & 5386.114 & 6612.622 & 8382.315 & 3833.702 & 3334.5 & 31832.71 & 5996.818 & 3014.542 & 20928.45 \\
\hline 2009 & 5325.49 & 6093.621 & 8217.059 & 3841.754 & 3333.54 & 30700.47 & 5820.656 & 2940.221 & 20976.53 \\
\hline 2010 & 5678.286 & 6365.203 & 8609.268 & 3939.107 & 3574.662 & 34758.4 & 5910.669 & 3163.901 & 22236.1 \\
\hline 2011 & 5848.985 & 6631.454 & 9029.003 & 4142.133 & 3760.07 & 36154.01 & 6010.414 & 3158.064 & 22883.83 \\
\hline 2012 & 5900.512 & 6845.76 & 9436.478 & 4253.118 & 3934.267 & 36482.65 & 6051.314 & 3352.533 & 23303.09 \\
\hline 2013 & 6010.788 & 6922.792 & 9748.82 & 4406.079 & 4108.28 & 37491.08 & 6090.268 & 3437.839 & 23875.18 \\
\hline 2014 & 5969.677 & 6843.915 & 9847.863 & 4549.395 & 4151.082 & 38087.89 & 6086.446 & 3451.332 & 24565.56 \\
\hline
\end{tabular}

